\title{
DIGITALISASI PENYELENGGARAAN PAUD
}

\author{
Mahkamah Brantasari \\ Universitas Widya Gama Mahakam Samarinda \\ Email:mahkamah@uwgm.ac.id
}

\begin{abstract}
ABSTRAK
Pada masa periode globalisasi 4.0 yang mengarah pada perkembangan teknologi dan informasi, memiliki dampak yang sangat besar bagi masyarakat untuk merubah perilaku yang bersifat manual kearah digital, keadaan penggunaan digital dalam kehidupan manusia sehari-hari di Revolusi Industri 4.0 terus mengalami peningkatan. Kegiatan pengabdian masyarakat kali ini dilaksanakan dengan mengadakan webinar, dan penulis sebagai salah satu narasumber pada webinar nasional tersebut yang diadakan oleh prodi PG PAUD UWGM Samarinda. Digitalisasi penyelenggaraan Paud, merupakan salah satu bentuk metode layanan yang harus segera dilaksanakan dengan tujuan untuk memudahkan para pengguna jasa Paud, agar mudah mengakses dan mendapatkan informasi seputar kegiatan yang dilakukan oleh Lembaga Paud yang bersangkutan. Kegiatan yang dapat dilakukan lembaga paud dalam penyelenggaraan yang digitalisasi sangat banyak misalnya saja dalam penggunaan website, Lembaga memanfaatkan website yang di buat untuk sarana promosi dengan mengupload kegiatan-kegiatan yang dibuat dan telah dilakukan sehingga dengan sendirinya aktivitas dapat di ketahui oleh masyarakat secara luas, kegiatan-kegiatan baik yang dilakukan tentu saja dapat meningkatkan prestasi dan prestise lembaga atau sekolah itu sendiri
\end{abstract}

Kata Kunci: Digitalisasi PAUD, PAUD masa pandemik covid-19

\section{PENDAHULUAN}

Pada masa periode globalisasi 4.0 yang mengarah pada perkembangan teknologi dan informasi, memiliki dampak yang sangat besar bagi masyarakat untuk merubah perilaku yang bersifat manual kearah digital. Semua kegiatan manusia mengarah pada teknologi yang bertugas untuk membantu dan meringankan kerja manusia dalam semua bidang kehidupan. Teknologi di rancang dan di buat sebagai tenaga pengganti dalam pemrosesan dan juga sebagai penggerak dalam kegiatan yang bersifat fisik dan juga non fisik. Globalisasi 4.0 menggabungkan antara kecanggihan teknologi dengan otomatisasinya dan teknologi cyber yaitu perangkat atau program jaringan yang bersifat bayangan. (Dwiningrum, 2012, p.155). Pada masa saat ini teknologi berkembang dengan pesat, meliputi berbagai aspek kehidupan manusia. Masa sekarang kehidupan manusia sulit di pisahkan dengan teknologi, karena teknologi telah menjadi kebutuhan manusia. Teknologi awalnya merupakan bagian dari ilmu atau bergantung dari ilmu, sekarang ilmu dapat pula bergantung dari teknologi. Contohnya dengan berkembang pesatnya teknologi komputer dan satelit ruang angkasa, maka diperoleh 
pengetahuan baru dari hasil kerja kedua produk teknologi tersebut. (Ngafifi, 2014)

Keadaan penggunaan digital dalam kehidupan manusia sehari-hari di Revolusi Industri 4.0 terus mengalami peningkatan. Peristiwa ini dapat ditemui di berbagai sektor keseharian masyarakat, seperti penggunaan teknologi digital komputer, permainan digital, digitalisasi pemakaian mata uang (e-money), pemakaian media digital (e-media), hingga berkembang pesatnya film berbasis digital. (Abdullah, 2019)

Dimasa pandemi covid-19 saat ini pengguna teknologi untuk kegiatan yang bersifat digitalisasi semakin meningkat pesat dalam segala bidang, salah satunya adalah dalam bidang pendidikan. Penggunaan teknologi terutama dalam pembelajaran dan juga penyimpanan datadata atau administrasi sekolah juga semakin meningkat. Pemanfaatan teknologi untuk memudahkan dalam pencarian dan penyimpanan data. Khusus dalam Pendidikan PAUD sangat penting untuk melakukan modernisasi dalam penyelenggaraan PAUD, yaitu dalam pengadministrasian peserta didik, tenaga pendidik dan kependidikan serta dalam pemperkenalkan intitusi/Lembaga paud yang dikelola.

\section{METODE}

Kegiatan pengabdian masyarakat kali ini dilaksanakan dengan mengadakan webinar, dan penulis sebagai salah satu narasumber pada webinar nasional tersebut yang diadakan oleh prodi PG PAUD UWGM Samarinda, yang dalam kegiatan tersebut dibuat susunan acara sebagai berikut:

\section{Susunan Acara Webinar}

Hari, Tanggal : Sabtu, 12 September 2020

Tempat : Link zoom cloud meeting dan streaming youtube

Waktu $\quad: 10.00-12.00$ WITA

\begin{tabular}{|l|l|l|l|}
\hline No & \multicolumn{1}{|c|}{ Waktu } & \multicolumn{1}{|c|}{ Kegiatan } & \multicolumn{1}{c|}{ Keterangan } \\
\hline 1 & $09.55-10.00$ & Registrasi peserta & $\begin{array}{l}\text { Link zoom meeting dan streaming } \\
\text { youtube akan dimulai 5 menit sebelum } \\
\text { jam 10.00 WITA }\end{array}$ \\
\hline 2 & $10.00-10.05$ & Pembukaan & $\begin{array}{l}\text { Mc membuka acara dan menjelaskan } \\
\text { rangkaian acara melalui link zoom } \\
\text { meeting dan streaming youtube. } \\
\text { Mc: Desi Hermawati, M.Pd }\end{array}$ \\
\hline 2 & $10.05-10.10$ & Doa & $\begin{array}{l}\text { Doa bersama untuk memulai kegiatan } \\
\text { yang akan dibawakan } \\
\text { Oleh: MC }\end{array}$ \\
\hline
\end{tabular}


Mahkamah. JPKPM. Vol.1(1). 39-45. Juni 2021

\begin{tabular}{|c|c|l|l|}
\hline 3 & $10.10-11.00$ & $\begin{array}{l}\text { Digitalisasi } \\
\text { Penyelengaraan } \\
\text { PAUD (Sesi tanya } \\
\text { jawab dan diskusi) }\end{array}$ & Mahkamah Brantasari, S.E., M.Pd \\
\hline 4 & $11.50-11.55$ & Penutupan MC & $\begin{array}{l}\text { MC akan menutupkan acara dan } \\
\text { mengarahkan untuk foto bersama }\end{array}$ \\
\hline 5 & $11.55-12.00$ & Doa & $\begin{array}{l}\text { Doa bersama untuk menutup kegiatan } \\
\text { yang akan dibawakan } \\
\text { Oleh: MC }\end{array}$ \\
\hline
\end{tabular}

Tabel 1.1 susunan acara webinar

\section{HASIL DAN PEMBAHASAN}

\section{Memberikan pemahaman mengenai digitalisasi penyelenggaraan PAUD}

Digitalisasi penyelenggaraan Paud, merupakan salah satu bentuk metode layanan yang harus segera dilaksanakan dengan tujuan untuk memudahkan para pengguna jasa Paud, agar mudah mengakses dan mendapatkan informasi seputar kegiatan yang dilakukan oleh Lembaga Paud yang bersangkutan. Dengan kemajuan dan perkembangan teknologi, sudah saatnya untuk melakukan pembaharuan pada sistem pelaksanaan manajemennya, agar Lembaga paud dalam aktivitas dan semua aksinya tidak tertinggal dengan Lembaga Pendidikan lainnya seperti Sekolah Dasar, Sekolah Menengah dan Perguruan Tinggi. Karena kemajuan adalah hak semua kalangan di segala bidang, maka layaklah Lembaga Paud pun sudah harus mengikuti kemajuan teknologi tersebut. Lev Manovich (2002) mengidentifikasi lima sifat khusus digital, yakni sesuatu yang diukur, dimonitor, dicatat, secara aritmatika; konsep memecah program menjadi modul yang berinteraksi antarmuka; otomatisasi, mengganti tenaga manusia dengan tenaga mesin; penyebaran nilai variable dari pusat datanya; dan transcoding, yaitu menggabungkan data yang ada menjadi satu format yang cocok. Menurutnya, teori digital selalu berkaitan erat dengan media, karena media terus berkembang seiring dengan majunya teknologi dari media lama sampai media terbaru, sehingga mempermudah manusia dalam segala bidang yang berkaitan dengan teori digital.(Aji, 2016)

Meskipun di masyarakat pada umumnya masih ada anggapan bahwa lembaga paud belum saatnya menggunakan teknologi informasi dan komunikasi dan bahkan mengatakan tidak penting melakukan penyelenggaraan paudnya dengan mengikut sertakan teknologi, dengan alasan, sekolahnya anak kecil saja, orangtua peserta didik masih banyak yang gagap teknologi, lembaga paud banyak yang berada pada lingkungan kalangan menengah kebawah, lembaga paud berada di pinggiran kota. Sehingga anggapan untuk penggunaan teknologi dianggap masih belum perlu. 
Anggapan tersebut hendaknya dijadikan penyemangat bagi pihak yang berkaitan dengan lembaga paud dan peduli terhadap Pendidikan anak usia dini, bahwa sebenarnya walaupun dengan banyaknya pandangan pesimis tersebut, bukan berarti kita sebagai pemeran pada pendidikan dunia anak mengabaikan dan tidak mengikuti perkembangan teknologi yang ada saat ini, justru berangkat dari anggapan pesimis tersebut lembaga paud harusnya terpacu untuk bisa mengoptimalkan digitalisasi penyelenggaraan paudnya. Tondeur et al (dalam Selwyn, 2011) yang menyatakan bahwa teknologi digital kini sudah mulai digunakan di dalam lembaga pendidikan sebagai pelengkap utama dalam pembelajaran, sebagai sarana mengakses informasi ataupun pemberi informasi dan juga sebagai sarana dan media dalam pembelajaran dan menyelesaikan tugas pembelajaran.(Lestari, 2018)

Karena dengan ketersediaan teknologi yang sedemikian maju dan modern, maka kita harus memanfaatkannya dengan banyak tujuan, salah satunya adalah memodernkan lembaga paud yang kita kelola, agar memudahkan pihak-pihak yang memiliki kepentingan terhadap lembaga paud yang kita kelola mudah dalam mengakses informasi yang mereka inginkan. Dalam (Ratminingsih, 2020: 1) menyatakan bahwa perkembangan teknologi didalam dunia pendidikan saat ini, baik informasi mengenai pengetahuan dan informasi yang berhubungan dengan pendidik dapat dengan mudah didapatkan oleh pendidik dan peserta didik melalui jaringan internet.(Mulyani1 \& Haliza2, 2021).

Kemajuan teknologi dapat lembaga paud manfaatkan untuk memudahkan lembaga dalam memperkenalkan dan mempromosikan lembaga paudnya pada masyarakat secara luas, karena memiliki jangkauan yang yang tidak berbatas. Hal ini tentu saja berimbas pada lembaga paud untuk tampil dalam memberikan pelayanan secara maksimal, sehingga menjadi motivasi lembaga paud menjadi lebih baik dalam kualitas pembelajaran dan kualitas pelayanan. Perubahan dalam hal layanan yang dapat kita lakukan misalnya saja dalam penerimaan peserta didik baru, yang mana pelayanan dan kemudahan pada saat pendaftaran dan juga proses administrasinya dapat dilakukan dengan mudah, tepat dan cepat. Transparansi dalam hal keuangan, program kerja, program belajar memudahkan dalam pengenalan visi dan misi Lembaga serta evaluasi dan kebijakan-kebijakan dalam pengambilan keputusan, semua dapat mudah di akses apabila lembaga telah mendigitalisasikan sistem penyelenggaraan paudnya. 


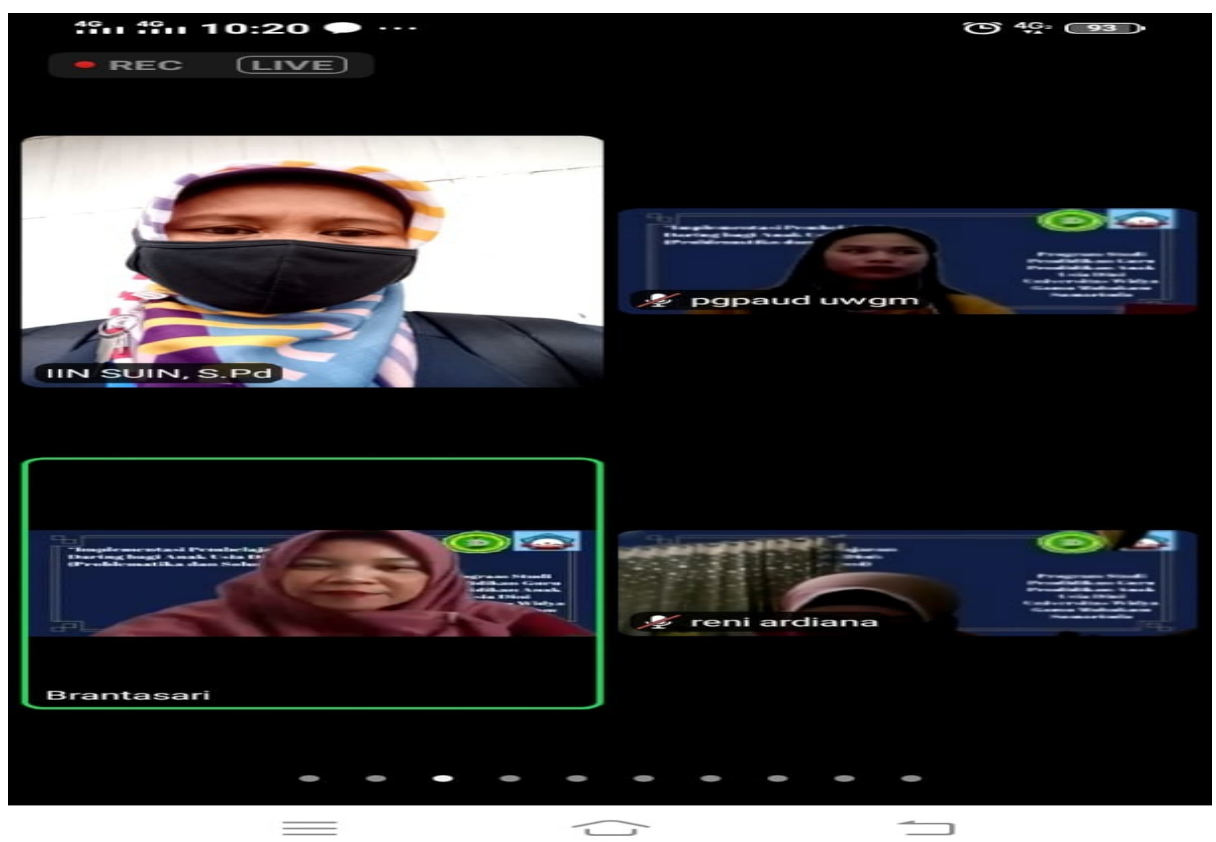

Gambar.1.1 Pelaksanaan webinar (dokumentasi pribadi)

\section{Memberikan contoh alternatif mengenai digitalisasi penyelenggaraan PAUD}

Lembaga dalam mendigitalisasikan penyelenggaraan paudnya dapat memutuskan media internet mana yang akan digunakan sebagai media digitalisasinya, apabila menggunakan website maka putuskan website apa yang digunakan, apakah bersifat dinamis atau yang bersifat statis, berbayar atau tidak berbayar. Apabila sudah di putuskan media internet yang di gunakan maka segera lakukan persiapan dan putuskan apa saja yang akan di tayangkan pada website yang di miliki.

Digitalisasi penyelenggaraan paud yang dilaksanakan sangat mendukung program pemerintah dalam hal pemanfaatan internet serta membangun mutu dalam pengelolaan dan penyelenggaraan paud. Kualitas dan mutu dari pendidik akan terus menyesuaikan dengan aktivitas yang dilaksanakan dalam pembelajaran sehingga model dan strategi dalam pembelajaran akan terus meningkat. Karena pembelajaran yang di berikan menggunakan aplikasi yang selalu berkembang maka kemampuan peserta didikpun akan terus meningkat seiring dengan pembelajaran yang di berikan.

Dalam pelaksanaan pembelajaran di paud yang terus mengembangkan diri dalam penggunaan internet, bisa saja menyebabkan peserta didik menjadi lebih antusias dalam belajar sehingga dapat mengurangi keinginan untuk bermain-main game di internet, kebaikankebaikan yang di dapat dalam digitalisasi inilah yang sudah seharusnya di kembangkan di masyarakat. 
Kegiatan yang dapat dilakukan lembaga paud dalam penyelenggaraan yang digitalisasi sangat banyak misalnya saja dalam penggunaan website, Lembaga memanfaatkan website yang di buat untuk sarana promosi dengan mengupload kegiatan-kegiatan yang dibuat dan telah dilakukan sehingga dengan sendirinya aktivitas dapat di ketahui oleh masyarakat secara luas, kegiatan-kegiatan baik yang dilakukan tentu saja dapat meningkatkan prestasi dan prestise lembaga atau sekolah itu sendiri. Contoh materi yang dapat disiapkan dalam pembuatan sebuah website lembaga atau sekolah diantaranya:

a) Profil Lembaga paud/sekolah, yang terdiri dari latar belakang berdirinya Lembaga atau sekolah, ada sejarah perkembangan Lembaga atau sekolah, visi misi, struktur organisasi lembaga atau sekolah, tenaga pendidik dan kependidikan serta yang terpenting juga adalah fasilitas yang ada pada lembaga atau sekolah.

b) Keakademikan, yaitu dengan penyampaian program Pendidikan, kurikulum yang dilaksanakan, kegiatan-kegiatan ekstrakurikuler yang menunjang kurikulum serta kalender Pendidikan yang mencerminkan kegiatan pembelajaran selama periodik Pendidikan.

c) Kesiswaan, yaitu dengan pemberitahuan Tata tertib Siswa, Kegiatan harian, Daftar siswa, Daftar Alumni

d) Kegiatan eksternal, yaitu kegiatan yang mendukung dan menujang kurikulum yang dilaksanakan, sesuai visi misi Lembaga/sekolah. Misalnya Kegiatan keagamaan, keolahragaan, pecinta alam, kunjungan Pendidikan dan lain sebagainya.

e) Informasi penting, misalnya saja berupa informasi tentang teknis Penerimaan siswa baru atau pendaftaran secara online, Pengumuman hasil ujian atau hasil seleksi, pemberitaan berupa artikel-artikel yang berhubungan dengan kegiatan Lembaga/sekolah beserta fotofoto kegiatan yang ada.

Keberadaan website Lembaga atau sekolah dapat juga di gunakan sebagai media pembelajaran yang dilaksanakan secara daring atau e-learning, juga dapat dijadikan wadah informasi materi pembelajaran, dengan demikian komunikasi dapat terus dilaksanakan walaupun tanpa bertemu langsung, forum diskusi dan tanya jawab dapat dilakukan secara daring atau online pada waktu yang telah di tetapkan. Aplikasi yang dapat di gunakan ada zoom, google meet, dan lain sebagainya. Dengan adanya website ini pendidik dapat menyalurkan ilmunya di media website lembaga atau sekolah sehingga variasi dalam pembelajaran menjadi banyak dan tidak membosankan.

Dengan dilaksanakannya digitalisasi dalam penyelenggaraan Lembaga paud, komunikasi elektronik dapat dilaksanakan pada instansi/Lembaga/sekolah, baik secara internal dan juga eksternal (antar Lembaga, dan juga masyarakat), website dapat gunakan sebagai media 
komunikasi antara pihak yang berkepentingan, misalnya sebagai media silaturahmi, berkirim pesan, kesan, saran dan sebagainya yang berhubungan dengan kepentingan informasi Lembaga yang bersangkutan. Sehingga informasi yang ada cepat tersampaikan kepada masyarakat, orangtua, maupun antar instansi, Lembaga, sekolah. Dan juga sebagai wadah suatu komunitas.

- Pembelajaran dari mana dan kapan saja (time and place flexibility).

- Bertambahnya Interaksi pembelajaran antara peserta didik dengan guru atau instruktur (interactivity enhancement).

\section{KESIMPULAN}

Digitalisasi penyelenggaraan paud yang dilaksanakan sangat mendukung program pemerintah dalam hal pemanfaatan internet serta membangun mutu dalam pengelolaan dan penyelenggaraan paud. Kualitas dan mutu dari pendidik akan terus menyesuaikan dengan aktivitas yang dilaksanakan dalam pembelajaran sehingga model dan strategi dalam pembelajaran akan terus meningkat. Karena pembelajaran yang di berikan menggunakan aplikasi yang selalu berkembang maka kemampuan peserta didikpun akan terus meningkat seiring dengan pembelajaran yang di berikan.

Kegiatan yang dapat dilakukan lembaga paud dalam penyelenggaraan yang digitalisasi sangat banyak misalnya saja dalam penggunaan website, Lembaga memanfaatkan website yang di buat untuk sarana promosi dengan mengupload kegiatan-kegiatan yang dibuat dan telah dilakukan sehingga dengan sendirinya aktivitas dapat di ketahui oleh masyarakat secara luas, kegiatan-kegiatan baik yang dilakukan tentu saja dapat meningkatkan prestasi dan prestise lembaga atau sekolah itu sendiri.

\section{DAFTAR PUSTAKA}

Abdullah, F. (2019). Fenomena Digital Era Revolusi Industri 4.0. Jurnal Dimensi DKV Seni Rupa Dan Desain, 4(1), 47. https://doi.org/10.25105/jdd.v4i1.4560

Aji, R. (2016). DIGITALISASI, ERA TANTANGAN MEDIA (Analisis Kritis Kesiapan Fakultas Dakwah Dan Komunikasi Menyongsong Era Digital). Islamic Communication Journal, 1(1), 43-54. https://doi.org/10.21580/icj.2016.1.1.1245

Lestari, S. (2018). PERAN TEKNOLOGI DALAM PENDIDIKAN DI ERA GLOBALISASI. Edureligia, 2(2), 94-100.

Mulyani1, F., \& Haliza2, N. (2021). Analisis Perkembangan Ilmu Pengetahuan dan Teknologi ( Iptek ) Dalam Pendidikan. JURNAL PENDIDIKAN Dan KONSELING, 3(1), 1001-1109.

Ngafifi, M. (2014). Kemajuan Teknologi Dan Pola Hidup Manusia Dalam Perspektif Sosial Budaya. Jurnal Pembangunan Pendidikan: Fondasi Dan Aplikasi, 2(1), 33-47. https://doi.org/10.21831/jppfa.v2i1.2616 